\title{
Correlation between carbonic anhydrase IX (CA-9), XII (CA-12) and hypoxia inducible factor-2a (HIF-2a) in breast cancer
}

\author{
J. JIANG ${ }^{1,2}$, J. H. ZHAO 2 , X. L. WANG ${ }^{3}$, X. J. GUO ${ }^{4}$, J. YANG ${ }^{2}$, X. BAI ${ }^{2}$, S. Y. JIN ${ }^{2}$, R. L. GE ${ }^{1, \star}$ \\ ${ }^{1}$ Research Center for High Altitude Medicine, Qinghai University, Xining 810001, P. R. China; ${ }^{2}$ Department of Oncology, Affiliated Hospital of \\ Qinghai University, Xining 810001, P. R. China; ${ }^{3}$ Operating room Affiliated Hospital of Qinghai University, Xining 810001, P. R. China; ${ }^{4}$ Depart- \\ ment of Pathology, Affiliated Hospital of Qinghai University, Xining 810001, P. R. China
}

${ }^{*}$ Correspondence: gerriligao@hotmail.com

Received August 11, 2014 / Accepted October 16, 2014

\begin{abstract}
Hypoxia inducible factor $2 \alpha$ (HIF-2 $\alpha$ ) can trigger the expression of several genes related to many aspects of tumor progress under hypoxia. As an independent factor, the role of HIF-2 $\alpha$ is different from other hypoxia-mediated elements, including HIF1a. Carbonic anhydrase (CA) were also regarded as important enzymes that involve in the tumor microenvironment $\mathrm{pH}$. To find clinical-pathological features of breast cancer in plateau and explore the impact of CAIX, XII (CA-9, CA-12) and HIF-2a on patients with breast cancer. Clinical data were collected and summarized in 94 patients with breast cancer. The expression of HIF-2 $\alpha$, CA-9 and CA-12 were detected, using immunohistochemistry of specimens. The relation between expressions and clinical-pathology was analyzed. Under normoxia, hypoxia, and after being pretreated with the JNK inhibitor SP600125, HIF$2 \alpha$, CA- 9 and CA-12 expressions were detected, and adhesion and invasion assays were performed in MCF-7 cells and HIF- $2 \alpha$ shRNA cells, respectively. There are higher expressions of HIF- $2 \alpha$ in tumor classification 2 and clinical stage $2(\mathrm{P}<0.05)$. High expression of CA-12 was observed in clinical stage $2(\mathrm{P}<0.05)$. CA-9 expression is significantly correlated with CA-12 expression $(\mathrm{r}=0.376, \mathrm{P}=0.0001)$. HIF-2 $\alpha$ expression is not correlated with both CA-9 expression $(\mathrm{P}=0.21)$ and CA-12 expression $(\mathrm{P}=0.27)$. Breast cancer cells in vitro showed that HIF-2 $\alpha, \mathrm{CA}-9$ or CA-12 had an increase expression under hypoxia $\left(1 \% \mathrm{O}_{2}\right)$. CA-9 or CA-12 expression was observed in HIF-2 $\alpha$ shRNA cells. JNK inhibitor SP 600125 reduced the HIF-2 $\alpha$ expression and inhibited the adhesion and invasion of breast cancer cell. Slight inhibition effect on CA-9 and CA-12 expression was found. In conclusion, HIF-2 $\alpha$, CA-9 and CA-12 are important hypoxia responsive elements in breast cancer. HIF- $2 \alpha$ was involved in metastasis and invasion of breast cancer cells under hypoxia, by the involvement of c-Jun NH2-terminal kinase (JNK) signal pathway. CA-9 and CA-12 may tend to be regulated by HIF-1 $\alpha$ more often than by HIF-2 $\alpha$ under hypoxia.
\end{abstract}

Key words: breast cancer, carbonic anhydrase, hypoxia

Breast cancer is the most frequently diagnosed cancer and the leading cause of cancer death among females worldwide $[1,2]$. Meanwhile, breast cancer is also a highly heterogeneous group of diseases that differ in their molecular and genetic trait, pathomorphological feature, clinical course, and response to treatment [2]. The incidence of breast cancer is increasing rapidly in China. According to data from China National Cancer Center, approximately 210,000 new cases were diagnosed with breast cancer and 55,000 cancer death death in 2012 [3]. Breast cancer is referred to as one of the most curable and treatable of all cancers. Despite tremendous strides in diagnosis and therapy, many patients died of recurrence and metastasis. Growth, invasion, and metastasis of tumor depend mainly on the features of tumor cells and their interactions with tumor microenvironment. Microenvironment may be an important and critical step in survival and growth of tumor cells. A great many reports described that solid tumors have a mismatch between metabolic demand and oxygen delivery, leading to local hypoxia and cellular energy crisis. This can give rise to the opinion that there is close relationship between hypoxia and cancer.

In the last two decades, the high incidence of breast cancer was noticed in Qinghai, a high altitude area in northwest China. Breast cancer has become one of the common cancers in this area. However, there has been the lack of clinicpathological and mechanism research information so far. Because Qinghai is located in a hypoxia and cold area, it is presumed that hypoxia 
may play one of important promotive role in breast cancer in the plateau. Hypoxia inducible factor (HIF- $\alpha$ ) has been reported that it mediates the transcriptional adaptation of hypoxic cells to these microenvironmental conditions [4]. Despite similar structures, HIF- $1 \alpha$ and HIF- $2 \alpha$ possess different transcriptional functions, because of differences in their $\mathrm{N}$-terminal activation domains and requirements of specific transcriptional cofactors [5]. HIF-1a has commonly been described to be essential for breast cancer growth, but the role HIF-2 $\alpha$ and it's downstream elements play in breast cancer is not still relatively well known. Carbonic anhydrase enzymes are universally involved in many fundamental physiological processes. CA-9 and CA-12 belong to transmembrane carbonic anhydrase enzymes, and are also regarded as important enzymes that are related to the tumor microenvironment PH. It is suggested that there is a relationship between HIF and carbonic anhydrase. To further explore their effect on breast cancer and the correlation among them in plateau area, the clinical-pathological features and expressions of HIF- $2 \alpha$ and carbonic anhydrase were studied in breast cancer patients who live in hypoxia area.

\section{Patients and methods}

Patients and tissue specimens. A total of 94 females with breast invasive ductal cancer were recruited over a period of two years. All patients have been lived in Qinghai high land for more than twenty years. All these patients were given detailed explanation and signed their informed consent prior to their inclusion in the study. This study was approved by the hospital ethics committee following the tenets of the Helsinki Declaration. Tumor tissue of each patient was obtained after undergoing surgery at the department of oncology surgery in the Affiliated Hospital of Qinghai University, China. The clinical, pathological, and estrogen receptor (ER), progesterone receptor (PR), and HER2 information were obtained. Two pathologist confirmed the diagnosis and characterized the tumor by reviewing haematoxylin and eosin (HE) slides. Clinical-pathological parameters were assessed [6] and are showed in Table 1.

Immunohistochemistry. All specimens from surgery department were fixed with formalin and embedded in

Table 1. HIF-2 $\alpha$, CAIX and CAXII expression in 94 patients with breast cancer

\begin{tabular}{|c|c|c|c|c|c|c|c|c|c|c|c|c|c|c|c|}
\hline \multirow{2}{*}{ Parameters } & \multicolumn{5}{|c|}{ HIF-2a } & \multicolumn{5}{|c|}{ CAIX } & \multicolumn{5}{|c|}{ CAXII } \\
\hline & Negative & $\%$ & Postive & $\%$ & $P$ value & Negative & $\%$ & Postive & $\%$ & $P$ value & Negative & $\%$ & Postive & $\%$ & $\mathrm{P}$ value \\
\hline Tumor classification & & & & & 0.048 & & & & & 0.856 & & & & & 0.063 \\
\hline $\mathrm{T} 1$ & 9 & 9.6 & 13 & 13.8 & & 9 & 9.6 & 13 & 13.8 & & 4 & 4.3 & 18 & 19.1 & \\
\hline $\mathrm{T} 2$ & 8 & 8.5 & 34 & 36.2 & & 14 & 14.9 & 28 & 29.8 & & 2 & 2.1 & 40 & 42.6 & \\
\hline T3 & 2 & 2.1 & 15 & 16.0 & & 8 & 8.5 & 9 & 9.6 & & 1 & 1.1 & 16 & 17.0 & \\
\hline $\mathrm{T} 4$ & 2 & 2.1 & 11 & 11.7 & & 4 & 4.3 & 9 & 9.6 & & 0 & 0.0 & 13 & 13.8 & \\
\hline Lymph node metastasis & & & & & 0.149 & & & & & 0.149 & & & & & 0.149 \\
\hline Negative & 16 & 17.0 & 38 & 40.4 & & 33 & 35.1 & 21 & 22.3 & & 5 & 5.3 & 49 & 52.1 & \\
\hline Positive & 5 & 5.3 & 35 & 37.2 & & 16 & 17.0 & 24 & 25.5 & & 2 & 2.1 & 38 & 40.4 & \\
\hline Stage & & & & & 0.003 & & & & & 0.975 & & & & & 0.036 \\
\hline 1 & 9 & 9.6 & 9 & 9.6 & & 7 & 7.4 & 11 & 11.7 & & 3 & 3.2 & 15 & 16.0 & \\
\hline 2 & 9 & 9.6 & 38 & 40.4 & & 17 & 18.1 & 30 & 31.9 & & 5 & 5.3 & 42 & 44.7 & \\
\hline 3 & 3 & 3.2 & 26 & 27.7 & & 11 & 11.7 & 18 & 19.1 & & 0 & 0.0 & 29 & 30.9 & \\
\hline Histological grade & & & & & 0.095 & & & & & 0.955 & & & & & 0.612 \\
\hline 1 & 5 & 5.3 & 10 & 10.6 & & 6 & 6.4 & 9 & 9.6 & & 1 & 1.1 & 14 & 14.9 & \\
\hline 2 & 14 & 14.9 & 45 & 47.9 & & 22 & 23.4 & 37 & 39.4 & & 4 & 4.3 & 34 & 36.2 & \\
\hline 3 & 2 & 2.1 & 18 & 19.1 & & 7 & 7.4 & 13 & 13.8 & & 2 & 2.1 & 39 & 41.5 & \\
\hline Ki-67 & & & & & 0.938 & & & & & 0.625 & & & & & 0.464 \\
\hline$\leq 14 \%$ & 7 & 7.4 & 25 & 26.6 & & 13 & 13.8 & 19 & 20.2 & & 1 & 1.1 & 31 & 33.0 & \\
\hline$>14 \%$ & 14 & 14.9 & 48 & 51.1 & & 22 & 23.4 & 40 & 42.6 & & 6 & 6.4 & 56 & 59.6 & \\
\hline Estrogen receptor & & & & & 0.68 & & & & & 0.122 & & & & & 0.860 \\
\hline Negative & 9 & 9.6 & 35 & 37.2 & & 20 & 21.3 & 24 & 25.5 & & 4 & 4.3 & 40 & 42.6 & \\
\hline Positive & 12 & 12.8 & 38 & 40.4 & & 15 & 16.0 & 35 & 37.2 & & 3 & 3.2 & 47 & 50.0 & \\
\hline Progestin receptor & & & & & 0.393 & & & & & 0.630 & & & & & 0.467 \\
\hline Negative & 9 & 9.6 & 39 & 41.5 & & 19 & 20.2 & 29 & 30.9 & & 5 & 5.3 & 43 & 45.7 & \\
\hline Positive & 12 & 12.8 & 34 & 36.2 & & 16 & 17.0 & 30 & 31.9 & & 2 & 2.1 & 44 & 46.8 & \\
\hline HER-2 & & & & & 0.808 & & & & & 0.157 & & & & & 0.424 \\
\hline Negative & 17 & 18.1 & 55 & 58.5 & & 24 & 25.5 & 48 & 51.1 & & 4 & 4.3 & 68 & 72.3 & \\
\hline Positive & 4 & 4.3 & 18 & 19.1 & & 11 & 11.7 & 11 & 11.7 & & 3 & 3.2 & 19 & 20.2 & \\
\hline $\begin{array}{l}\text { Lymphovascular } \\
\text { invasion }\end{array}$ & & & & & 0.974 & & & & & 0.963 & & & & & 0.679 \\
\hline Negative & 9 & 9.6 & 31 & 34.0 & & 15 & 16.0 & 20 & 21.3 & & 4 & 4.3 & 36 & 38.3 & \\
\hline Positive & 11 & 12.0 & 42 & 44.7 & & 25 & 26.6 & 34 & 36.2 & & 3 & 3.2 & 51 & 54.3 & \\
\hline
\end{tabular}


paraffin. The sections were mounted onto histostickcoated slides after being sectioned at $4 \mu \mathrm{m}$. Histopathological analysis (hematoxylin and eosin stain) and immunohistochemical (IHC) staining were performed. This method has been described previously in detail [7]. Briefly, the sections were deparaffinized in xylene and dehydrated in descending dilutions of ethanol; endogenous peroxidase activity was blocked by incubating in $0.3 \% \mathrm{H}_{2} \mathrm{O}_{2}$ for $30 \mathrm{~min}$. Antigen retrieval was performed by treating the slides in citrate buffer in a microwave for 10 minutes. The sections were incubated with HIF-2a mouse monoclonal antibody (1:200, Chemicon) at $4^{\circ} \mathrm{C}$ overnight. The slides were incubated in biotin-labeled goat anti-mouse antibody for $30 \mathrm{~min}$ at $37^{\circ} \mathrm{C}$ after being washed by phosphate buffer solution (PBS), followed by the incubation with avidin-biotin peroxidase complex for $30 \mathrm{~min}$ at $37^{\circ} \mathrm{C}$. The signal was collected using diaminobenzidine as the chromogen for 8 minutes. Negative controls were established by replacing the primary antibody with PBS or normal mouse IgG1 (BD PharMingen).

Scoring of immunohistochemistry. Immunohistochemical scoring of HIF-2 $\alpha$, CA-9, CA-12 was graded in a double-blind manner by two independent pathologists, according to the standards reported previously $[7,8]$. HIF- $2 \alpha$ expression was present mainly in nucleus, and CA-9 and CA- 12 in membrane. The proportion and intensity of positive cells were used to quantify expression of these factors. Scores were performed as follows: score 0 , negative staining in all cells; score $1+$, weakly positive or focally positive staining in $<2 \%$ of the cells; score $2+$, moderately positive staining covering $>2-10 \%$ of the cells; and score $3+$, strongly positive staining in $>10 \%$ of the cells (Figure 1). Expression was considered positive for scores of $2+$ or $3+$.

Cell culture in normoxia and hypoxia. The MCF-7 breast carcinoma cell line was obtained from Chinese Academy Science. The cell line was maintained in RPMI 1640 medium containing $10 \%$ fetal bovine serum with sodium pyruvate, $100 \mathrm{IU} / \mathrm{mL}$ penicillin, $100 \mu \mathrm{g} / \mathrm{mL}$ streptomycin, and $2 \mathrm{mmol} / \mathrm{L}$ glutamine (Life Technologies, Paisley, United Kingdom) at $37^{\circ} \mathrm{C}$ in a humidified atmosphere of $5 \% \mathrm{CO} 2$ and $95 \%$ air. For hypoxia treatment, the MCF-7 breast carcinoma cell line was cultured under hypoxia at $37^{\circ} \mathrm{C}$. The system was set up with an atmosphere of $1 \% \mathrm{O}_{2}, 5 \% \mathrm{CO}_{2}$, and $94 \% \mathrm{~N}_{2}$, and all solutions were preequilibrated for at least $12 \mathrm{~h}$ before each experiment.

shRNA delivery and stable transduction by a lentiviral vector. The shRNA expression vector for HIF- $2 \alpha$ and the clones generation of stable transfection was previously reported [9]. A selfinactivating lentiviral vector system was used. Five short RNA sequences targeting HIF- $2 a$ gene (Genbank accession no NM_001430.4) were designed and listed in Table 2. These RNA hairpins were cloned into the pLLU2G vector (American Type Culture Collection, Virgin-

\section{HIF $2-\alpha$}
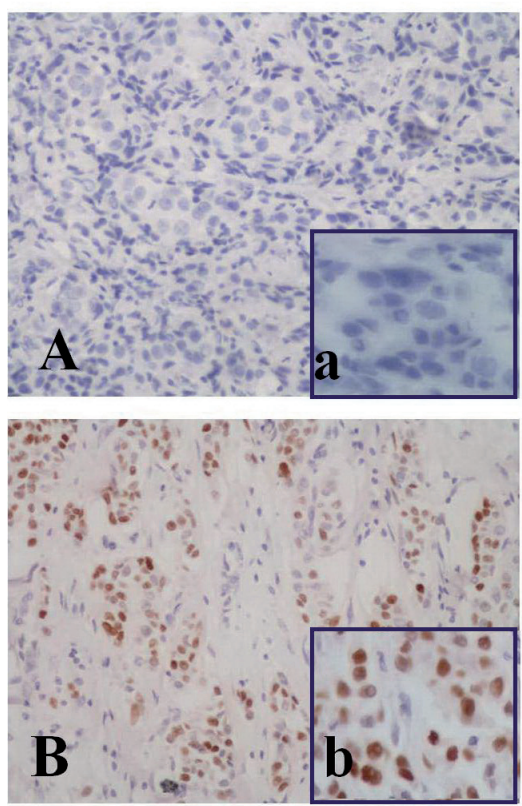

CA-9
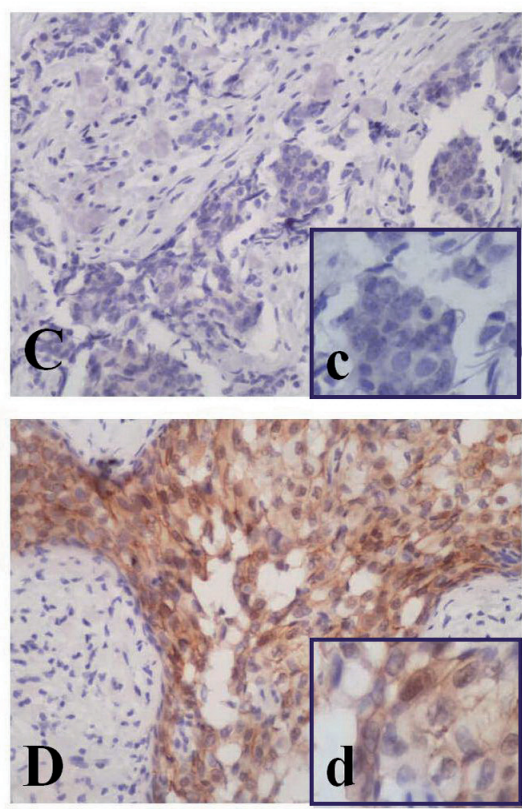

$\mathrm{CA}-12$
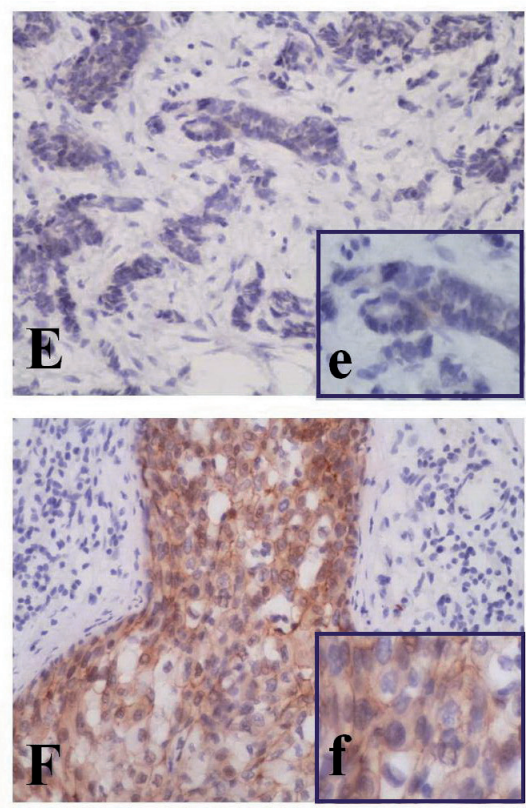

Figure 1. Representative staining results of HIF-2 $\alpha$, CA-9 and CA-12 in breast cancer.

Immunohistochemistry for HIF-2 $\alpha, \mathrm{CA}-9$ and CA-12 was performed on 94 breast cancer specimens. Representative staining results are shown in Figure 1. Negative expression of three factors showed in A, C and E (SP 200×). Positive expression showed in B, D and F (SP 200×). Figures a - $f$ corresponding to A-F showed theses results in SP $400 \times$. 
Table 2. Oligo sequences of shRNA interference to HIF-2 $\alpha$

\begin{tabular}{ll}
\hline Oligo & Oligo sequence 5'to 3' \\
\hline shHIF-2a-1- F & TGCCCGGATAGACTTATTGCCAACTCGAGTTGGCAATAAGTCTATCCGGGTTTT \\
shHIF-2a-1- R & TCGAAAAACCCGGATAGACTTATTGCCAACTCGAGTTGGCAATAAGTCTATCCGGGCA \\
shHIF-2a-2- F & TGCAGCATCTTTGATACCAGTTTCAAGAGAACTGGTATCAAAGATGCTGTTTT \\
shHIF-2a-2- R & TCGAAAAACAGCATCTTTGATACCAGTTCTCTTGAAACTGGTATCAAAGATGCTGCA \\
shHIF-2a-3- F & TGCAGTACCCAGACGGATTTCAACTCGAGTTGAAATCCGTCTGGGTACTGTTTT \\
shHIF-2a-3- R & TCGAAAAACAGTACCCAGACGGATTTCAACTCGAGTTGAAATCCGTCTGGGTACTGCA \\
shHIF-2a-4- F & TGAGGTGGAGCTAACAGGACATACTCGAGTATGTCCTGTTAGCTCCACCTTTTT \\
shHIF-2a-4- R & TCGAAAAAAGGTGGAGCTAACAGGACATACTCGAGTATGTCCTGTTAGCTCCACCTCA \\
shHIF-2a-5- F & TGCGACCTGAAGATTGAAGTGATCTCGAGATCACTTCAATCTTCAGGTCGTTTT \\
shHIF-2a-5- R & TCGAAAAACGACCTGAAGATTGAAGTGATCTCGAGATCACTTCAATCTTCAGGTCGCA \\
Negative- F & TGCGCGCTTTGTAGGATTCGTTCAAGAGACGAATCCTACAAAGCGCGC TTTTTTC \\
Negative-R & TCGAGAAAAAAGCGCGCTTTGTAGGATTCGTCTCTTGAACGAATCCTACAAAGCGCGCA \\
\hline
\end{tabular}

ia, USA) under the control of polymerase-III U6-RNA gene promoter, respectively. This vector contains a cytomegalovirus (CMV) - enhanced green fluorescent protein (EGFP) expression cassette downstream of the U6 promoter that is used as a reporter gene to monitor infection intensity.

HEK293T cells were transfected with the pLLU2G plasmid and packaging vectors using Lipofectamine 2000 (Invitrogen, California, USA). The lentiviral packing vectors were pCMVdR8.91 and pVSV-G (Invitrogen, California, USA). The supernatant was collected after $36 \mathrm{~h}$. The titer was about $6 \times 10^{8}$ infectious units per milliter. Lentiviral transduction of MCF-7 cells was accomplished by cells plated in six-well plates for $8 \mathrm{~h}$ in the presence of $4 \mu \mathrm{g} / \mathrm{ml}$ polybrene (Sigma, California, USA). The MCF-7 cells were harvested $24 \mathrm{~h}$ after transfection and subject to hypoxia for 12 to $24 \mathrm{~h}$.

Adhesion and invasion assay. The detailed methods of adhesion and invasion were described previously [10]. The adhesion for MCF-7 breast cancer cells, stably transfected MCF-7 and MCF-7 cells pretreated with SP600125, was measured in 24-well plates coated with matrigel. $0.2 \mathrm{ml}$ matrigel $(50 \mu \mathrm{g} / \mathrm{ml})$ covered the plate surface and was incubated for $2 \mathrm{~h}$. The supernatant was removed after incubation. A $0.5 \mathrm{ml}$ suspension of cells $\left(1 \times 10^{5} / \mathrm{ml}\right)$ was placed into the plate. The plate was incubated for $2 \mathrm{~h}$ under normoxia and hypoxia, followed by wash with PBS. Adhesive cells were counted under a microscope at $200 \times$ magnification, for 10 random fields in each well. The invasion of these cells was performed using 24well transwell ( $8 \mathrm{~mm}$ pore size, Corning Costar Corp., Acton, MA, USA). $50 \mu \mathrm{l}$ matrigel $(2 \mathrm{mg} / \mathrm{ml})$ covered the surface of the upper compartment of a 24 -well transwell. The 24-well transwell was incubated for $5 \mathrm{~h}$. Cells were added to the matrigel of the upper compartments, and $700 \mu$ of DMEM containing $10 \%$ bovine serum was added into the lower chamber. After incubation for $24 \mathrm{~h}$ under normoxia or hypoxia, cells that had invaded the bottom were fixed with methanol and stained with hematoxylin. Invasiveness was determined by counting the penetrating cells. Each experiment was performed in triplicate.
Statistical analysis. Data were processed by the SPSS 19.0 software (Chicago, IL). $\mathrm{X}^{2}$-test was used to analyze the association between the expression of HIF-2 $\alpha$, CA-9, CA12 and clinical-pathological parameters. Correlation between HIF- $2 \alpha$ and CA was analyzed using Spearman's Rank Correlation. Results were considered statistically significant when the $\mathrm{p}$ value was less than 0.05 .

\section{Results}

Correlation between clinical-pathological characteristics and HIF-2 $\alpha$, CA-9, CA-12 expression in breast cancer. 94 patients with breast cancer aged $49.0 \pm 9.1$ years, from 32 to 75 years. Of all patients, $50 \%$ were diagnosed in clinical stage 2. $19.1 \%$ were in stage 1 , and $30.9 \%$ were in stage 3 . Tumor classification 2 had 44 patients (44.7\%), which was the highest. $40(42.6 \%)$ had Lymph node metastasis. Other features were shown in Table 1.

Immmunohistochemistry was performed for HIF-2 $\alpha$, CA-9, CA-12 on 94 specimens, aged. As shown in Figure 1, HIF-2 $\alpha$ staining appeared in the nucleus, whereas staining of CA-9 and CA-12 was seen at the plasma membrane. Of 94 specimens, HIF-2 $\alpha$ positive staining was observed in 73 (77.7\%) specimens. CA-9 and CA-12 were positive in 48 (51.1\%) and $87(92.6 \%)$ cases, respectively. The expressions of HIF-2 $\alpha$ were higher in tumor classification 2 (T2) than in other tumor classifications $(\mathrm{P}<0.05)$. In clinical stage 2 cases, CA-12 and HIF-2 $\alpha$ were more strongly expressed relative to other clinical stages $(\mathrm{P}<0.05)$. No significant difference of three factors expression was found in nodal status and progestin status. In positive lymphovascular invasion specimens, HIF-2 $\alpha$ and CA-9 expressions were high. This difference is significant. The detailed information is showed Table 1.

CA-9 and CA-12 are positively coexpressed with HIF-2 $\alpha$ in 45 cases. CA-9 expression is significantly correlated with CA-12 expression ( $r=0.376, \mathrm{P}=0.0001)$. However, HIF-2 $\alpha$ expression was not correlated with CA-9 expression $(\mathrm{P}=0.21)$. No correlation was found between HIF-2 $\alpha$ and CA-12 $(\mathrm{P}=0.27)$. 
CA-12 expression was not correlated with the histological grade.

HIF-2 $\alpha$ shRNA interference sequence selection. Five shRNA expression vectors for HIF-2 $\alpha$, and generation of stable transfection subclones were successfully performed. These shRNA duplexes to HIF- $2 a$ were evaluated by the western blot. The most efficient sequence for silencing HIF- $2 \alpha$ was the first sequence targeting nucleotides 1,302 to 1,322 (5'CCCGGATAGACTTATTGCCAA). Four shRNA sequences from HIF-2 $\alpha$ shRNA 2-5 and nonsilencing control expressed under hypoxia condition, compared with HIF-2a shRNA 1 . So stable transfection subclones for HIF-2 $\alpha$ shRNA 1 and negative control were utilized in sequent experiments.

HIF-2a, CA-9 and CA-12 expression in breast cancer MCF-7 cell line. HIF-2 $\alpha$ expression of the breast cancer cell line MCF-7 was detected under hypoxia $\left(1 \% \mathrm{O}_{2}\right)$ and normoxia for $0.5,4,8,12,24 \mathrm{~h}$. Results were shown in Figure 2. HIF-2a expression was no found under normoxia. HIF- $2 a$ showed an increase expression under hypoxia $\left(1 \% \mathrm{O}_{2}\right)$ from 0.5 to $48 \mathrm{~h}$. The HIF-2 $\alpha$ level at $0.5 \mathrm{~h}$ was observed to be lower than that from 4 to $48 \mathrm{~h}$, but no distinctive difference was found from 4 to $48 \mathrm{~h}$ (Figure $2 \mathrm{~B}$ ). HIF-2 $\alpha$ was not expressed in HIF- $2 \alpha$ shRNA inference cell line from 0.5 to $48 \mathrm{~h}$, but an increase expression was seen under hypoxia in HIF-2 $\alpha$ shRNA control.

CA- 9 and CA-12 expression of the breast cancer cell line MCF-7 was also observed in Figure 2. Two factors were ex-

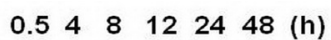

$\begin{array}{lllllll}0.5 & 4 & 8 & 12 & 24 & 48 & (h)\end{array}$

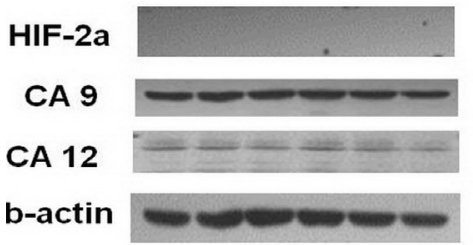

A

$\begin{array}{lllllll}0.5 & 4 & 8 & 12 & 24 & 48 & (h)\end{array}$

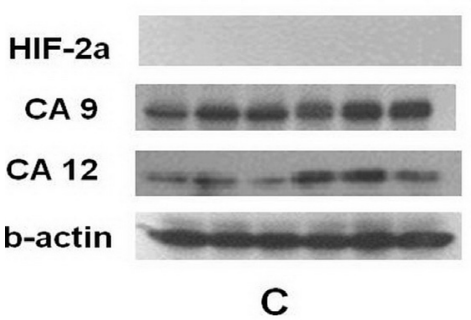

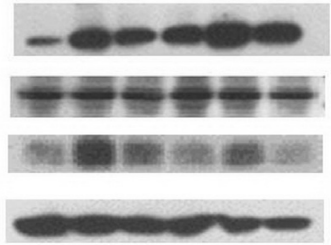

B
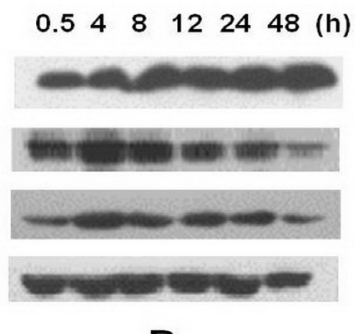

Figue 2. HIF-2 $\alpha$, CA-9, CA-12 expression in the breast cancer cell and HIF-2 $\alpha$ shRNA inference cell.

A. HIF-2 $\alpha$, CA-9 and CA-12 expression in the breast cancer cell line MCF-7 under normoxia for $0.5,4,8,12,24,48 \mathrm{~h}$; B. HIF-2 $\alpha$, CA-9 and CA-12 expression in the breast cancer cell line MCF-7 under hypoxia ( $1 \%$ $\mathrm{O}_{2}$ ) for $0.5,4,8,12,24,48 \mathrm{~h}$; $\mathrm{C}$. Three factors expression in HIF-2 $\alpha$ shRNA interference cell line under $1 \% \mathrm{O}_{2}$; D. Three factors expression in HIF-2a shRNA interference control cell line under $1 \% \mathrm{O}_{2}$. pressed under both normoxia and hypoxia. Under normoxia, CA-9 expression was distinctively unchanged from 0.5 to 48 h. Under hypoxia, the CA-9 level was stable while HIF-2a had an increase expression from 0.5 to $48 \mathrm{~h}$. CA-9 from HIF- $2 a$ shRNA interference cell line was unchanged as well, while no HIF-2 $\alpha$ was expressed. CA-12 expression was found for $48 \mathrm{~h}$ hypoxia. The level at $4 \mathrm{~h}$ was similar to be higher than that at other period, in consistent with the increase level of HIF-2a. Compared with CA-9, CA-12 expression was lower in the same cell line.

Role of c-Jun NH2-terminal kinase in HIF-2a, CA-9, CA-12 expression and adhesion and invasion. The Breast cancer MCF-7 cells were cultured and pretreated with different concentrations $(5 \mu \mathrm{M}, 25 \mu \mathrm{M}$, respectively) of SP600125 for $4 \mathrm{~h}$ and then exposed to $1 \%$ oxygen for $12 \mathrm{~h}$. The HIF- $2 \mathrm{a}$ expression attenuated from the cells pretreated with $25 \mu \mathrm{m}$ SP600125. There was a significant dose-dependent inhibition of HIF-2 $\alpha$ expression in breast cancer cell pretreated with the specific JNK inhibitor (Figure $3 \mathrm{~A}$ ). No expression was found in HIF-2 $\alpha$ shRNA interference MCF-7 cells pretreated with SP600125. However, HIF-2a shRNA interference control cells showed the same change in the HIF-2 $\alpha$ expression (Figure $3 \mathrm{~B}$ and C). CA-9 and CA-12 levels were stable in different concentration of SP600125, but their hypoxia expressions were high compared to normoxia.

Under hypoxia, the adhesive abilities of MCF-7 and HIF- $2 a$ shRNA control cells were decreased after inhibition by $25 \mu \mathrm{M}$ SP600125, higher than that of HIF-2 $\alpha$ shRNA interference cells. Inhibiting rates of adhesion were $46.8 \%, 42.4 \%, 31.8 \%$, respectively. Similarly, the invasive abilities of MCF-7, MCF-7 HIF- $2 \alpha$ shRNA control cells and HIF- $2 \alpha$ shRNA interference cells were decreased. Inhibiting rates of invasion were $47.1 \%$, $43.8 \%, 34.7 \%$, respectively.

\section{Discussion}

HIF- $2 \alpha$ has been confirmed to be a closely related protein that involves in tumor microenvironment of the growth and the invasion. Several studies showed that chronically hypoxic tumor areas would be marked by enhanced HIF- $2 a$ levels. Blancher et al reported HIF- $2 \alpha$ has a broader spectrum of expression, and a reduced inducibility of HIF-2 $\alpha$ is correlated with an increased survival of the breast cancer cell lines under hypoxia [11]. In the present study, HIF-2 $\alpha$ showed an increase expression in breast cancer cell under hypoxia $\left(1 \% \mathrm{O}_{2}\right)$, but no distinctive difference was found from 4 to $48 \mathrm{~h}$. The result is consistent with great many studies. Meanwhile, the clinicalopathologic profile was first studied on breast cancer patients who live in plateau. Results showed that $50 \%$ patients were diagnosed in clinical stage 2. Data on breast cancer in the East of England showed that $45 \%$ were in Stage 2 [12]. It is worth noting that $46.6 \%$ of positive HIF- $2 \alpha$ expression was in patients with T2, which is higher compared with T1, T3 and T4. 52.1\% was in patients in tumor stage 2 . These might indicate that HIF-2 $a$ plays tumor growth promotive role mainly during 
stage 1-2. Morrow et al reported that tumors cannot grow greater than 1-2 $\mathrm{mm}^{3}$ without angiogenesis because the lack of oxygen in the center of the tumor results in apoptosis and necrosis [13]. Blancher et al found also HIF-2 $\alpha$ overexpression significantly impaired tumor growth, and thought that a balance between the tumor-activating and tumor-inhibiting levels of HIF proteins may be necessary for optimal tumor growth [11]. Meanwhile, other more hypoxia-responsive factors may participate in tumor growth and invasion. CA enzymes involve in the tumor microenvironment $\mathrm{PH}$ by catalyzing the reversible hydration of carbon dioxide to bicarbonate and proton. Several studies revealed that CA-9 expression is correlated with high tumor grade and increased tumor size in breast cancer $[14,15]$. In this research, positive incidence of CA-12 expression was also highest in clinical stage 2 , similar to HIF$2 \alpha$. These results indicated HIF-2 $\alpha$ and CA effect biphasic regulation on breast cancer.

CA-9 and CA-12 expression may have closer relationship with HIF-1 $\alpha$ than with HIF-2a under hypoxia. HIF-2a was described as an endothelial-specific factor homologous to HIF$1 \alpha$ [16]. Blancher et al reported HIF-2 $\alpha$ is commonly expressed in breast cancer cell lines and is not therefore endothelial specific [11]. Indeed, most cells express two independent hypoxia transcription factors that regulate VEGF expression. It is proposed that HIF-2 $\alpha$ regulation for CA may be different from HIF-1a. CA-9 has a conserved core HIF-binding site with a G/ ACGTG consensus sequence. This sequence is also the most critical regulatory element in the CA-9 promoter. Experimental evidence showed that the CA-9 promoter was transactivated in a HIF-1 $\alpha$-dependent manner under hypoxia [17]. In this study, there were high positive expressions of CA-9 and HIF-2 $\alpha$ in clinical breast cancer specimens, but no correlation between them was found. Cell in vitro studied revealed that CA-9 level was slight and stable under normoxia. The stable and higher expression was observed under hypoxia while HIF-2a had an increase expression. The results also showed that CA-9 from HIF-2 $\alpha$ shRNA interference cell was significantly unchanged as well, while no HIF-2 $\alpha$ was expressed. CA-12 is also a member of the carbonic anhydrase family. It is regarded as involving in the acidification of the extracellular microenvironment, which is suitable for rapid tumor growth. The CA-12 expression was detected in various human cancers, such as pancreatic, ovarian and breast cancer. Higher CA-12 expression was also correlated with a better overall and disease-specific survival in patients with resectable non-small-cell lung cancer [18]. Our experimental data showed that the CA12 expression is not correlated with HIF-2 $\alpha$ in clinical specimens. CA-12 expression was found for $48 \mathrm{~h}$ hypoxia in breast cancer cell. The level was consistent with the increase level of HIF-2 $\alpha$. Integrating these results, CA- 9 and CA-12 are hypoxia responsive elements, but HIF-2 $\alpha$ induces their expression to a small extent. We think that CA- 9 and CA-12 may tend to be regulated by HIF-1 $1 \alpha$ more often than by HIF-2 $\alpha$ under hypoxia. The CA-9 and CA-12 factors had slight expression under normoxia in this study, which is different from other reports. Ivanov SV et al described
CA-9 is practically active under normoxia, when tumor cells have a mutant or epigenetically silenced[19]. Two factors are
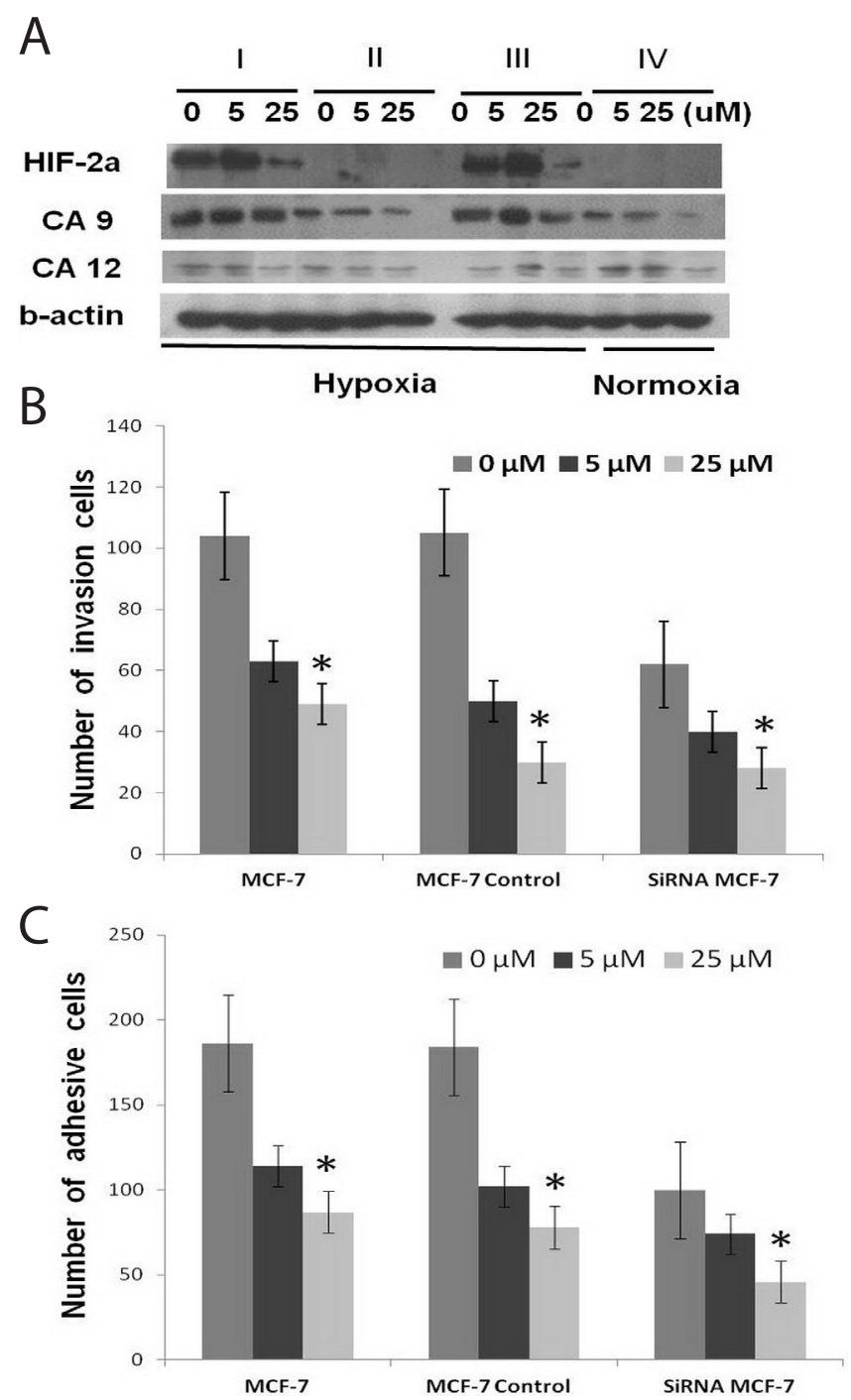

Figure 3. JNK inhibition effect on the HIF-2a, CA-9 and CA-12 expression of the breast cancer cell.

A: I. Breast cancer MCF-7 cells were cultured and pretreated with different concentrations of SP600125 for $4 \mathrm{~h}$ and then exposed to $1 \%$ oxygen for $12 \mathrm{~h}$. II and III. HIF- $2 \alpha$ shRNA MCF-7 cells and HIF-2 $\alpha$ shRNA control cells were cultured and pretreated with different concentrations of SP600125 for $4 \mathrm{~h}$ and then exposed to $1 \%$ oxygen for $12 \mathrm{~h}$, respectively. IV. Breast cancer MCF-7 cells were cultured and pretreated with different concentrations of SP600125 for $4 \mathrm{~h}$ under normoxia. Cells were harvested and the HIF-2 $\alpha$, CA-9 and CA-12 expression were determined by western blot analysis. $\beta$-actin was used as an internal control.

B: Adhesion assay to evaluate the effect of JNK specific inhibitor SP600125 $(5 \mu \mathrm{M}$ and $25 \mu \mathrm{M})$ on adhesive ability of MCF-7cells, HIF-2 $\alpha$ shRNA control cells and HIF-2 $\alpha$ shRNA interference cells under hypoxic condition by counting cells attaching to Matrigel under a microscope. C: Invasive assay was used to evaluate the effect of SP600125 (5 $\mu \mathrm{M}$ and $25 \mu \mathrm{M})$ on invasive ability of MCF-7cells, HIF-2 $\alpha$ shRNA control cells and HIF- $2 \alpha$ shRNA interference cells under hypoxic condition by counting cells invading through matrigel and membrane with $8 \mu \mathrm{m}$ pore of transwell. ${ }^{\star} \mathrm{p}<0.05$. 
needed to maintain the balance of tumor microenvironment $\mathrm{PH}$ under both normoxia and hypoxia.

HIF- $1 \alpha$ and HIF-2 $\alpha$ display similar induction by acute hypoxia, but they were differentially regulated during prolonged hypoxia [20]. The stabilization and transcriptional activation of the HIF-a protein involve in their phosphorylation states. HIF- $\alpha$ inductions regulated by signaling pathway is only partly understood. Some data have demonstrated that multiple signaling mechanisms regulate HIF- $\alpha$ induction under hypoxia. Accumulating evidence suggests that JNK activation leads to altered HIF-1 $\alpha$ activity. It is reported that extracellular requlated kinase (ERK) play an important role in the induction of HIF-1 $\alpha$ activity and expression. Recent studies found that JNK is involved in HIF-1 $\alpha$ and HIF-2 $\alpha$-related adhesion and invasion induced by hypoxia. There was a significant inhibition of hypoxia-induced HIF-1 $\alpha$ and HIF-2 $\alpha$ expression in gastric cancer cells pretreated with the specific JNK inhibitor SP600125 [21]. Xu et al described that HIF-1 $\alpha$ is necessary for DNA damage and apoptosis by JNK[22]. In this study, the adhesive and invasive abilities were detected in MCF-7, HIF-2 $\alpha$ shRNA control cells, HIF-2 $\alpha$ shRNA interference cells, respectively. The adhesion and invasion of MCF-7 cells were decreased after being pretreated with SP600125. HIF-2a shRNA interference cells were observed to have low adhesive and invasive abilities, compared with MCF-7 cells. After inhibition by SP600125, the adhesion and the invasion showed a lower level than before. These results support that JNK is involved in HIF-1 $\alpha$ and HIF$2 \alpha$-related adhesion and invasion induced by hypoxia in breast cancer cell. There was a dose-dependent inhibition of HIF- $2 a$ expression in breast cancer cell pretreated with the specific JNK inhibitor in this study. However, HIF-2a shRNA interference control cells showed the same change in the HIF-2a expression. CA-9 and CA-12 levels were stable in different concentration of SP600125, but their hypoxia expressions were high compared to normoxia. These results provided evidence that HIF-2a has a growth promoting effect on breast cancer cells, through a mechanism that, at least in part, involves the activation of the JNK pathway. It is more unlikely that CA-9 and CA-12 expression may be mainly regulated by HIF- $2 \alpha$.

Acknowledgements: This study was supported by National Nature Science Foundation of China (NO. 31160219).

\section{References}

[1] JEMAL A, BRAY F, CENTER MM, FERLAY J, WARD E, et al. Global cancer statistics. CA Cancer J Clin 2011; 61: 69-90. http://dx.doi.org/10.3322/caac.20107

[2] BERNARD W. STEWART, CHRISTOPHER P. WILD. International Agency for Research on Cancer. World cancer report. 2014. pp.509.

[3] HE J, CHEN WQ. Chinese Cancer Registry Annual Report 2012 by National Cancer Center \& Disease Prevention and Control Bureau, Ministry of Health. Beijing: Military Medical Science Press., 2012.
[4] BERTOUT JA, PATEL SA, SIMON MC. The impact of O2 availability on human cancer. Nat Rev Cancer 2008; 8: 967-975. http://dx.doi.org/10.1038/nrc2540

[5] HU YY, FU LA, LI SZ, CHEN Y, LI JC, et al. Hif-1alpha and Hif-2alpha differentially regulate Notch signaling through competitive interaction with the intracellular domain of Notch receptors in glioma stem cells. Cancer Lett 2014; 349: 67-76. http://dx.doi.org/10.1016/j.canlet.2014.03.035

[6] SINGLETARY SE, CONNOLLY JL. Breast cancer staging: working with the sixth edition of the AJCC Cancer Staging Manual. CA Cancer J Clin 2006; 56: 37-47; quiz 50-51.

[7] BIRCAN S, CANDIR O, KAPUCUOGLU N, SEREL TA, CIRIS M, et al. CD10 expression in urothelial bladder carcinomas: a pilot study. Urol Int 2006; 77: 107-113. http://dx.doi. org/10.1159/000093901

[8] AOMATSU N, YASHIRO M, KASHIWAGI S, KAWAJIRI H, TAKASHIMA T, et al. Carbonic anhydrase 9 is associated with chemosensitivity and prognosis in breast cancer patients treated with taxane and anthracycline. BMC Cancer 2014; 14: 400. http://dx.doi.org/10.1186/1471-2407-14-400

[9] CHAVEZ JC, BARANOVA O, LIN J, PICHIULE P. The transcriptional activator hypoxia inducible factor 2 (HIF-2/EPAS-1) regulates the oxygen-dependent expression of erythropoietin in cortical astrocytes. J Neurosci 2006; 26: 9471-9481. http:// dx.doi.org/10.1523/JNEUROSCI.2838-06.2006

[10] THAMILSELVAN V, BASSON MD. Pressure activates colon cancer cell adhesion by inside-out focal adhesion complex and actin cytoskeletal signaling. Gastroenterology 2004; 126: 8-18. http://dx.doi.org/10.1053/i.gastro.2003.10.078

[11] BLANCHER C, MOORE JW, TALKS KL, HOULBROOK S, HARRIS AL. Relationship of hypoxia-inducible factor (HIF)1alpha and HIF-2alpha expression to vascular endothelial growth factor induction and hypoxia survival in human breast cancer cell lines. Cancer Res 2000; 60: 7106-7113.

[12] LYRATZOPOULOS G, ABEL GA, BARBIERE JM, BROWN $\mathrm{CH}$, ROUS BA, et al. Variation in advanced stage at diagnosis of lung and female breast cancer in an English region 2006-2009. Br J Cancer 2012; 106: 1068-1075. http://dx.doi. org/10.1038/bjc. 2012.30

[13] MORROW CS, COWAN KH. Antineoplastic drug resistance and breast cancer. Ann N Y Acad Sci 1993; 698: 289-312. http://dx.doi.org/10.1111/j.1749-6632.1993.tb17220.x

[14] SPAN PN, BUSSINK J, MANDERS P, BEEX LV, SWEEP CG. Carbonic anhydrase-9 expression levels and prognosis in human breast cancer: association with treatment outcome. Br J Cancer 2003; 89: 271-276. http://dx.doi.org/10.1038/ sj.bjc. 6601122

[15] CHIA SK, WYKOFF CC, WATSON PH, HAN C, LEEK RD, et al. Prognostic significance of a novel hypoxia-regulated marker, carbonic anhydrase IX, in invasive breast carcinoma. J Clin Oncol 2001; 19: 3660-3668.

[16] TIAN H, MCKNIGHT SL, RUSSELL DW. Endothelial PAS domain protein 1 (EPAS1), a transcription factor selectively expressed in endothelial cells. Genes Dev 1997; 11: 72-82. http://dx.doi.org/10.1101/gad.11.1.72

[17] WYKOFF CC, BEASLEY NJ, WATSON PH, TURNER KJ, PASTOREK J, et al. Hypoxia-inducible expression of 
tumor-associated carbonic anhydrases. Cancer Res 2000; 60: 7075-7083.

[18] ILIE MI, HOFMAN V, ORTHOLAN C, AMMADI RE, BONNETAUD C, et al. Overexpression of carbonic anhydrase $\mathrm{XII}$ in tissues from resectable non-small cell lung cancers is a biomarker of good prognosis. Int J Cancer 2011; 128: 1614-1623. http://dx.doi.org/10.1002/ijc.25491

[19] IVANOV SV, KUZMIN I, WEI MH, PACK S, GEIL L, et al. Down-regulation of transmembrane carbonic anhydrases in renal cell carcinoma cell lines by wild-type von Hippel-Lindau transgenes. Proc Natl Acad Sci U S A 1998; 95: 12596-12601. http://dx.doi.org/10.1073/pnas.95.21.12596

[20] KOH MY, LEMOS R JR, LIU X, POWIS G. The hypoxiaassociated factor switches cells from HIF-1alpha- to
HIF-2alpha-dependent signaling promoting stem cell characteristics, aggressive tumor growth and invasion. Cancer Res 2011; 71: 4015-4027. http://dx.doi.org/10.1158/0008-5472. CAN-10-4142

[21] WANG Y, LI Z, ZHANG H, JIN H, SUN L, et al. HIF-1alpha and HIF-2alpha correlate with migration and invasion in gastric cancer. Cancer Biol Ther 2010; 10: 376-382. http:// dx.doi.org/10.4161/cbt.10.4.12441

[22] XU Y, LI Y, LI H, PANG Y, ZHAO Y, et al. The accumulations of HIF-1alpha and HIF-2alpha by JNK and ERK are involved in biphasic effects induced by different levels of arsenite in human bronchial epithelial cells. Toxicol Appl Pharmacol 2013; 266: 187-197. http://dx.doi.org/10.1016/j. taap.2012.11.014 